\title{
Stage II neuroblastoma. Adverse prognostic significance of lymph node involvement
}

\author{
J NINANE, J PRITCHARD, P H MORRIS JONES, J R MANN, AND J S MALPAS \\ The Hospital for Sick Children and Institute of Child Health, London; Royal Manchester Children's Hospital; \\ Children's Hospital, Birmingham; St Bartholomew's Hospital, London
}

SUMMARY Thirty-three children aged between 1 month and 16 years (median 1 year, 7 months), were treated for stage II neuroblastoma with surgery, radiotherapy, or chemotherapy, alone or in combination. After 3 years $70 \%$ were living, 6 children had died from the disease, and 4 had died as a result of treatment. Patient characteristics (age, gender) and tumour characteristics (primary site, presence of lymph node involvement, catecholamine excretion, histology) were reviewed in an attempt to determine prognostic features. While age under 1 year at diagnosis was, as expected, favourable in this series, the most important prognostic variable was the presence or absence of regional lymph node involvement. No patient with uninvolved nodes died of neuroblastoma and the difference in the 3-year survival rate between these patients and those with positive nodes was statistically significant. Although this study of patients treated between 1970 and 1977 provided no clear evidence that either postoperative radiotherapy or contemporary chemotherapy was of benefit, our findings suggest that subclassification of stage II patients into ' node-positive' and ' nodenegative' groups will help to define those who might benefit from improved adjuvant postsurgical treatment.

According to the clinical staging system of Evans et al. ${ }^{1}$ stage II neuroblastoma, accounting for $15 \%$ of all patients with this malignancy, ${ }^{2} 3$ is a tumour extending in continuity beyond the organ or structure of origin but not crossing the midline and without evident metastases. Homolateral lymph nodes may be affected. Although this system has been widely used since 1971, it is still not understood why up to $25 \%$ of patients with stage II tumours eventually die from the disease ${ }^{45}$ nor is it understood why they are distinguished from the remainder. In an attempt to clarify some of the factors we have carried out a retrospective analysis of clinical, biochemical, and histopathological characteristics of 33 patients with stage II neuroblastoma.

\section{Patients and methods}

Selection of cases. We reviewed the records of all patients with non-metastatic neuroblastoma admitted between January 1970 and September 1977. Patients with stage I and III disease, using Evans's criteria, were excluded. A diagnosis of stage II neuroblastoma was made in 33 children admitted to our four institutions. There were 19 girls and 14 boys with ages ranging from 1 month to 16 years (median
1 year, 7 months). All patients were diagnosed by histological examination of the primary tumour and all underwent chest $x$-ray films, intravenous pyelogram, skeletal survey or radionuclide bone scan, and 24-hour urine collections for vanillylmandelic acid (VMA). Twenty-nine ( $88 \%$ ) patients underwent bone marrow aspiration and $26(79 \%)$ had a radionuclide liver scan. Similar studies were also regularly performed for 3 years after diagnosis. None of the children was lost to follow-up when the study ended in January 1981. The minimum follow-up period was $3 \frac{1}{2}$ years.

Tumour characteristics. The primary site was abdominal in $16(49 \%)$ patients, mediastinal in 11 $(33 \%)$, pelvic in $4(12 \%)$, and cervical in $2(6 \%)$. Fifteen ( $45 \%$ ) children presented with a 'dumb-bell' tumour and $13(39 \%)$ had homolateral lymph node involvement. Urinary VMA excretion was increased in $27(82 \%)$ patients while histological study showed a diagnosis of neuroblastoma in $25(76 \%)$ and of ganglioneuroblastoma in $8(24 \%)$ cases.

Lymph node sampling. All obviously enlarged regional lymph nodes were removed at the time of surgery. Normal-looking lymph nodes were not 
necessarily sampled and there was no attempt to carry out formal dissection of non-adjacent nodes in areas where these appeared macroscopically normal.

Treatment. The different combinations of three treatment modalities were as follows: surgery alone, $4(12 \%)$; radiotherapy alone, $2(6 \%)$; surgery plus chemotherapy, $3(9 \%)$; surgery plus radiotherapy, $13(40 \%)$; radiotherapy plus chemotherapy, $4(12 \%)$; and surgery plus radiotherapy plus chemotherapy, $7(21 \%)$. Of the $27(82 \%$ of the total) children who underwent surgery, 18 had partial resection of tumour and 9 had complete resection. Twenty-six $(79 \%)$ children were treated with radiotherapy, starting within 14 days of operation. Radiation was given at a dose of 150-200 cGy/day, 5 days each week. The total dose varied between 2000 and 3500 cGy. Chemotherapy, administered to only 14 patients, was given 2- to 3-weekly for 6 months to 2 years and consisted of cyclophosphamide (2 patients), vincristine (1 patient), cyclophosphamide and vincristine (6 patients), and cyclophosphamide, vincristine, and adriamycin (5 patients).

Statistical analysis. Analysis of prognostic variables (Table 2) and results was by the $\chi^{2}$ method.

\section{Results}

Of the 33 children, 23 are alive and free of disease between 42 and 129 (median 79) months after diagnosis, giving an overall survival of $70 \%$ (Fig. 1).

Six patients died from tumour between 2 and 26 months after diagnosis; their clinical courses are shown in Table 1. Four deaths were caused by treatment, 2 in the immediate postoperative period and 2 at a later date from adriamycin cardiomyopathy with no evidence of tumour. Of the last 2 patients, the first was a 6-year-old girl with an unresectable mediastinal tumour. She was treated with radiotherapy (2000 cGy in 10 fractions over 14 days) and chemotherapy. She died one year after start of treatment. At that time she had been given a total dose of $680 \mathrm{mg} / \mathrm{m}^{2}$ adriamycin. The second child was a 9-year-old boy who had a partial resection of a mediastinal 'dumb-bell' neuroblastoma. He was also treated with radiotherapy $(3500 \mathrm{cGy}$ in 18 fractions over 28 days) and chemotherapy. He died 9 months later after having received $520 \mathrm{mg} / \mathrm{m}^{2}$ adriamycin.

\section{Prognostic features (Table 2, Fig. 1).}

\section{Lymph node invasion}

While 4 of the 20 patients without lymph node involvement died of treatment-related complications, none died of neuroblastoma (Fig. 2). By contrast, 6 of the 13 node-positive patients-and all involved nodes were, by definition, homolateral-subsequently died of recurrent or metastatic tumour. This difference in survival was statistically significant $(P<0 \cdot 01)$.

\section{Age}

As expected, children under age 1 year at diagnosis fared better $(P<0.05)$ than older patients; all tumour-related deaths were in the latter group.

\section{Histology}

No patient with ganglioneuroblastoma died from tumour but the difference in survival between these children and those with neuroblastoma was not statistically significant.

\section{Other features}

The gender of the patient, presence or absence of VMA excretion, and site of primary tumour were of no prognostic significance.

Treatment (Table 3). Patients dying of treatment

Table 1 Characteristics and clinical course of patients who died from neuroblastoma

\begin{tabular}{|c|c|c|c|c|c|c|}
\hline & \multicolumn{6}{|l|}{ Cases } \\
\hline & 1 & 2 & 3 & 4 & 5 & 6 \\
\hline $\begin{array}{l}\text { Sex } \\
\text { Age (years) } \\
\text { Primary } \\
\text { Lymph nodes } \\
\text { Histology } \\
\text { Surgery (resection) } \\
\text { Radiotherapy (c-Grays) } \\
\text { Chemotherapy } \\
\text { Response } \\
\text { Relapse (years from diagnosis) } \\
\text { Death (years from diagnosis) }\end{array}$ & $\begin{array}{l}\text { M } \\
11 / 12 \\
\text { Pelvis } \\
+ \\
\text { Neuroblastoma } \\
- \\
4000 \\
\text { CVA } \\
\text { Partial } \\
\overrightarrow{4 / 12}\end{array}$ & $\begin{array}{l}\text { M } \\
9 \\
\text { Pelvis } \\
\quad+ \\
\text { Neuroblastoma } \\
\overrightarrow{3300} \\
0 \\
\text { Partial } \\
\overrightarrow{2 / 12}\end{array}$ & $\begin{array}{l}\text { F } \\
11 / 12 \\
\text { Abdomen } \\
+ \\
\text { Neuroblastoma } \\
\text { Partial } \\
3000 \\
0 \\
\text { Partial } \\
\overline{9 / 12}\end{array}$ & $\begin{array}{l}\text { M } \\
43 / 12 \\
\text { Abdomen } \\
+ \\
\text { Neuroblastoma } \\
\text { Partial } \\
3000 \\
0 \\
\text { Complete } \\
8 / 12 \\
12 / 12\end{array}$ & $\begin{array}{l}\text { F } \\
611 / 12 \\
\text { Abdomen } \\
+ \\
\text { Neuroblastoma } \\
\text { Complete } \\
0 \\
0 \\
\text { Complete } \\
18 / 12 \\
22 / 12\end{array}$ & $\begin{array}{l}\text { M } \\
17 / 12 \\
\text { Cervical } \\
+ \\
\text { Neuroblastoma } \\
\text { Partial } \\
2000 \\
\text { CVA } \\
\text { Partial } \\
\overline{4 / 12}\end{array}$ \\
\hline
\end{tabular}

CVA $=$ cyclophosphamide + vincristine + adriamycin 


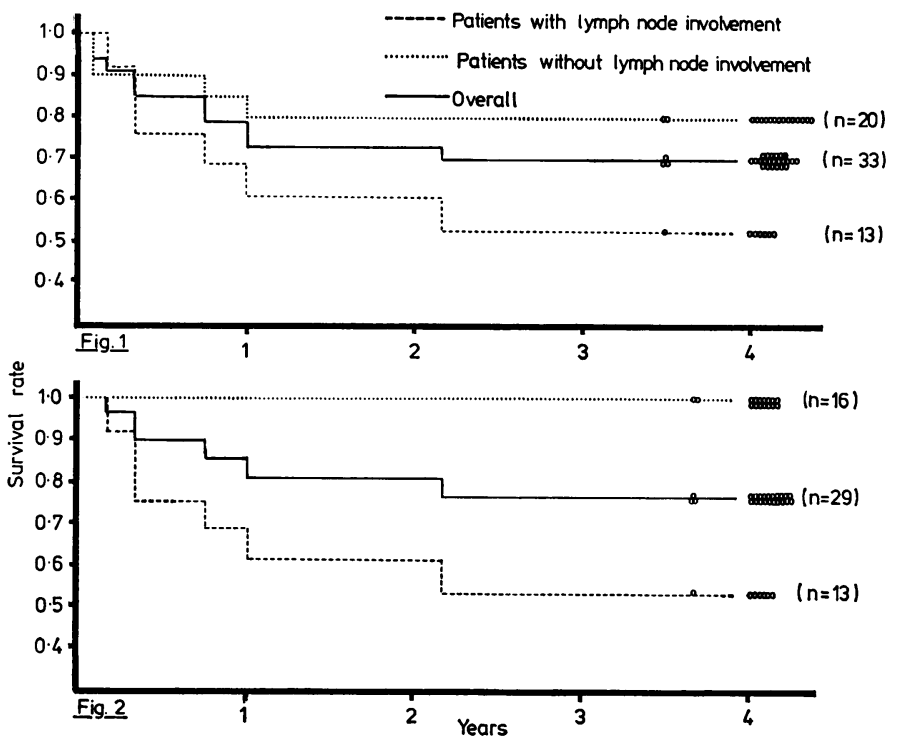

Fig. 1 'Life-table' of 33 patients with stage II (Evans) neuroblastoma.

Open circles denote disease-free survivors; patients surviving 4 years or longer are grouped together at the end of each curve.

Fig. 2 Tumour-related 'life-table' of patients with stage II neuroblastoma (excludes children who died from side effects of treatment).

Table 2 Prognostic features

\begin{tabular}{|c|c|c|c|c|c|c|}
\hline \multirow[b]{2}{*}{ Sex } & \multirow[b]{2}{*}{$\begin{array}{l}\mathbf{M} \\
\mathbf{F}\end{array}$} & \multicolumn{2}{|c|}{$\begin{array}{l}\text { Overall 3-year } \\
\text { survival rate }\end{array}$} & \multicolumn{2}{|c|}{$\begin{array}{l}\text { Tumour-related } \\
\text { survival rate* }\end{array}$} & \multirow{2}{*}{$\begin{array}{l}\text { P value } \dagger \\
\text { NS }\end{array}$} \\
\hline & & $\begin{array}{r}9 / 14 \\
14 / 19\end{array}$ & $\begin{array}{l}(0.64) \\
(0.74)\end{array}$ & $\begin{array}{r}9 / 12 \\
14 / 17\end{array}$ & $\begin{array}{l}(0.82) \\
(0.75)\end{array}$ & \\
\hline \multicolumn{7}{|c|}{ Primary site } \\
\hline & $\begin{array}{l}\text { vical } \\
\text { diastinal }\end{array}$ & $\begin{array}{l}1 / 2 \\
8 / 11\end{array}$ & $\begin{array}{l}(0.5) \\
(0.73)\end{array}$ & $\begin{array}{l}1 / 2 \\
8 / 9\end{array}$ & $\begin{array}{l}(0.5) \\
(0.89)\end{array}$ & \\
\hline & $\begin{array}{l}\text { dominal } \\
\text { vic }\end{array}$ & $\begin{array}{c}11 / 16 \\
3 / 4\end{array}$ & $(0.69)$ & $\begin{array}{c}11 / 14 \\
3 / 4\end{array}$ & $(0.79)$ & NS \\
\hline \multicolumn{7}{|c|}{ Lymph nodes } \\
\hline & itive & $7 / 13$ & $(0.54)$ & $7 / 13$ & $(0 \cdot 54)$ & \\
\hline \multicolumn{7}{|c|}{ VMA } \\
\hline & $\begin{array}{l}\text { ised } \\
\text { rmal }\end{array}$ & $\begin{array}{c}18 / 27 \\
5 / 6\end{array}$ & $\begin{array}{l}(0.67) \\
(0.83)\end{array}$ & $\begin{array}{c}16 / 23 \\
5 / 6\end{array}$ & $\begin{array}{l}(0.74) \\
(0.83)\end{array}$ & NS \\
\hline \multicolumn{7}{|c|}{ Age } \\
\hline & $\begin{array}{l}\text { year } \\
\text { year }\end{array}$ & $\begin{array}{r}9 / 10 \\
14 / 23\end{array}$ & $\begin{array}{l}(0.90) \\
(0.61)\end{array}$ & $\begin{array}{c}9 / 9 \\
14 / 20\end{array}$ & $\begin{array}{l}(1 \cdot 0) \\
(0 \cdot 70)\end{array}$ & $<0.05$ \\
\hline \multicolumn{7}{|c|}{ Histology } \\
\hline & $\begin{array}{l}\text { nglioneuro- } \\
\text { lastoma } \\
\text { uroblastoma }\end{array}$ & $\begin{array}{c}6 / 8 \\
17 / 25\end{array}$ & $\begin{array}{l}(0.75) \\
(0.68)\end{array}$ & $\begin{array}{c}6 / 6 \\
17 / 23\end{array}$ & $\begin{array}{l}(1 \cdot 0) \\
(0.74)\end{array}$ & NS \\
\hline
\end{tabular}

* Bxcluding patients who died from non-tumour related causes (that is treatment). $\nmid \chi^{2}$ test, $1 \mathrm{df} ; \mathrm{NS}=$ non significant.

complications were excluded from our analysis of the influence of treatment on tumour-related survival.

\section{Surgery}

Three-year survival after partial resection (88\%) was as good as after complete resection ( $81 \%$ ). Since the proportion of patients in the two groups receiving postoperative radiotherapy or chemotherapy was similar (Table 3), this effect was not
Table 3 Effect of treatment on survival of 29 patients*

\begin{tabular}{lrrr} 
& $\begin{array}{l}\text { No of } \\
\text { patients }\end{array}$ & $\begin{array}{l}\text { 3-year } \\
\text { survivors }\end{array}$ & $\%$ \\
\hline Surgery & & & \\
$\quad$ Biopsy only & 5 & 3 & 60 \\
$\quad$ Complete resection & 16 & 13 & 81 \\
$\quad$ Partial resection & 8 & 7 & 88 \\
Radiotherapy & 5 & 4 & 80 \\
$\quad$ No & 24 & 19 & 79 \\
$\quad$ Yes & 17 & 13 & 78 \\
Chemotherapy & 12 & 10 & 83 \\
$\quad$ No & 9 & 7 & 78 \\
$\quad$ Yes & 6 & 4 & 67 \\
Radiotherapy + chemotherapy & 7 & 3 & 43 \\
Lymph node-positive patients & 9 & 4 & 44 \\
$\quad$ With chemotherapy & Without chemotherapy & 3 & 75 \\
$\quad$ With radiotherapy & & & \\
Without radiotherapy & 4 & & \\
\hline
\end{tabular}

*Four treatment-related deaths excluded.

apparently related to more energetic adjuvant therapy in those cases where only partial resection was possible.

\section{Radiotherapy}

The number or children not receiving radiotherapy was small but survival $(80 \%)$ in this group was no worse than that of radiation-treated children $(79 \%)$. This applied whether or not lymph nodes were affected.

Chemotherapy

Because of the length of this study and because of 
individual physicians' preferences, there was considerable heterogeneity in the chemotherapy regimens administered. There was no apparent advantage, in terms of tumour-related survival, for chemotherapy-treated patients compared with those not receiving this treatment. However, there was a trend in favour of postoperative chemotherapy in patients whose regional lymph nodes were involved by tumour (67 compared with $43 \%$ survival).

\section{Discussion}

Accurate staging of patients with neuroblastoma is essential for prognosis and for determining the most appropriate treatment. ${ }^{6}$ In 1971 Evans et al. ${ }^{1}$ proposed a clinical staging system which has become widely accepted. Stage II is used to designate regional extension of tumour that does not cross the midline. In this series of 33 children with stage II neuroblastoma, $6(18 \%)$ died from their disease. Our figures are comparable with those previously published $^{2} 45$ and suggest that there may be characteristic differences between patients with stage II disease who eventually die from the tumour and those who do not.

The most important single prognostic feature in our series was the presence of positive homolateral lymph nodes at diagnosis. While no patient without node involvement died from neuroblastoma, the survival rate of node-positive patients was only $0.54 \%$. Although the adverse prognostic significance of regional lymph node involvement in patients with localised Wilms's tumour has been appreciated for a number of years, ${ }^{78}$ few analyses have focused on the possible importance of regional node involvement in localised neuroblastoma. However, the conclusion of a recent study at St Jude Hospital, published in abstract form, ${ }^{9}$ was similar to our own. The possible reasons for less favourable survival in node-positive patients include a biologically more aggressive type of tumour or some failure of host-defence mechanisms in these children.

Age at diagnosis was another feature of prognostic value; our results are thus at variance with a recent report claiming that the effect of age appears insignificant in a small series of patients with localised thoracic tumours. ${ }^{10}$ On the contrary, we agree with others that stage and age are independent variables and that children aged under 1 year at diagnosis fare better than older children. ${ }^{2} 61112 \mathrm{~A}$ third variable of prognostic value in this series was histology; patients with localised ganglioneuroblastoma fared better than those with neuroblastoma but the difference was not statistically significant (Table 2). Increased maturation of localised neuro- blastoma has also been related to more favourable prognosis in two recent studies..$^{13} 14$

Other variables-such as gender, site of primary, and VMA secretion-were of no prognostic value. A high ratio of VMA to homovanillic acid (HVA) excretion seems to correlate with a better prognosis than the inverse ratio..$^{15}$ Since HVA estimation was not available during the 1970-77 period we were unable to analyse the prognostic value of the VMA/ HVA ratio in our patients.

Except in one small subgroup of patients, postoperative chemotherapy or radiotherapy did not improve disease-free survival compared with surgery alone (Table 3). Only patients with lymph node involvement fared somewhat better if they were treated with chemotherapy. Although the difference was not statistically significant, chemotherapy regimens were, by present-day standards, often 'gentle' in these patients. These data confirm the results of similar studies of treatment for localised neuroblastoma; there is no evidence to support the notion that patients treated with postoperative radiotherapy or single agent chemotherapy or both have a better survival rate than those who undergo surgery alone. ${ }^{410}$ In the only report claiming $100 \% 2$-year disease-free survival for 11 children treated with radiotherapy or chemotherapy after resection of a localised mediastinal neuroblastoma, there was no control group treated by surgery alone for comparison. ${ }^{16}$

The risks of adriamycin treatment after thoracic radiation are now better appreciated than in the 1970-77 period and the 2 adriamycin/radiationrelated deaths would probably not now occur. In addition, it has been shown, ${ }^{17}$ and recently confirmed by us, ${ }^{18}$ that adriamycin does not improve the survival rate in patients with advanced (stages III and IV) neuroblastoma when added to pulsed cyclophosphamide-vincristine-DTIC or to pulsed cyclophosphamide-vincristine. Thus, although adriamycin cardiomyopathy can be detected early by regular radionuclide assessment of left ventricular ejection fraction $^{19}$ and its incidence much reduced by limiting the total cumulative dose to $400 \mathrm{mg} / \mathrm{m}^{2}$ when the myocardium has been irradiated, ${ }^{20}$ this drug cannot be recommended for patients with localised disease.

We conclude that surgery alone seems to be adequate treatment for patients with stage II neuroblastoma without lymph node involvement. Patients with positive regional (homolateral) nodes, on the other hand, comprise a group at increased risk of developing recurrent or metastatic disease which should, we believe, be distinguished from the node-negative group in any staging system used. Until the tumour-node-metastasis staging system, ${ }^{21}$ which incorporates information about node status, 
is more widely accepted we suggest the use of a modification to the familiar Evans's system, whereby node-negative patients are classified as stage IIA and node-positive patients as stage IIB. Whatever nomenclature is eventually adopted, randomised controlled studies should be carried out to determine whether more aggressive chemotherapy might improve survival for Evans stage II patients whose regional nodes are invaded by tumour.

We thank Karine Delleuse and Elisabeth Moore for secretarial assistance.

$\mathbf{J} \mathbf{N}$ and $\mathbf{J} \mathbf{P}$ were supported by the Leukaemia Research Fund.

\section{References}

1 Evans A E, D'Angio G J, Randolph J. A proposed staging for children with neuroblastoma. Cancer 1971; 27: 374-8.

2 Jaffe N. Neuroblastoma: review of the literature and an examination of factors contributing to its enigmatic character. Cancer Treat Rev 1976; 3: 61-82.

3 Kinnier Wilson L M, Draper G J. Neuroblastoma, its natural history and prognosis. A study of 487 cases. Br Med J 1974; iii: 301-7.

4 Koop C E, Johnson D G. Neuroblastoma: an assessment of therapy in reference to staging. $J$ Pediatr Surg 1971; 6: 595-600.

5 Evans A E, Albo V, D'Angio G J, et al. Cyclophosphamide treatment of patients with localized and regional neuroblastoma. Cancer 1976; 38: 655-60.

6 Evans A E. Staging and treatment of neuroblastoma. Cancer 1980; 45: 1799-802.

7 Jereb B, Tournade M F, Lemerle J, et al. Lymph node invasion and prognosis in nephroblastoma. Cancer 1978; 45: $1632-6$.

8 Breslow N E, Palmer N F, Hill L R, Buring J, D'Angio G J. Wilms' tumor: prognostic factors for patients without metastases at diagnosis. Results of the National Wilms' Tumor Study. Cancer 1978; 41 : 1577-89.

9 Hayes F A, Green A A, Hustu H O, Kumar M. Surgicalpathological staging of neuroblastoma; importance of node metastases (abstract C 271). Proc Am Soc Clin Oncol 1981; 22: 401.
10 Castleberry R P, Crist W M, Cain W S, Holbrook T, Malluh A, Salter M M. Management of localized thoracic neuroblastoma. Med Pediatr Oncol 1979; 7: 153-61.

11 Evans A F, Albo V, D'Angio G J, et al. Factors influencing survival of children with non-metastatic neuroblastoma. Cancer 1976; 38: 661-6.

12 Coldman A J, Fryer C J H, Elwood J M, Sonley M J. Neuroblastoma. Influence of age at diagnosis, stage, tumour site, and sex on prognosis. Cancer 1980; 46: 1896-901.

13 Adam A, Hochholzer L. Ganglioneuroblastoma of the posterior mediastinum. A clinicopathologic review of 80 cases. Cancer 1981; 47: 373-81.

14 Punt J, Pritchard J, Pincott J R, Till K. Neuroblastoma: a review of 21 cases presenting with spinal cord compression. Cancer 1980; 45: 3095-101.

15 Laug W E, Siegel S E, Shaw K N F, Landing B, Baptista J, Gutenstein M. Initial urinary catecholamine metabolite concentration and prognosis in neuroblastoma. Pediatrics 1978; 62: 79-83.

16 Filler R M, Traggis D G, Jaffe N, Vawter G F. Favorable outlook for children with mediastinal neuroblastoma. J Pediatr Surg 1972; 7: 136-43.

17 Finklestein J Z, Klemperer M R, Evans A, et al. Multiagent chemotherapy for children with metastatic neuroblastoma. A report from the Children's Cancer Study Group. Med Pediatr Oncol 1979; 6: 179-88.

18 Ninane J, Pritchard J, Malpas J S. Chemotherapy of advanced neuroblastoma: does adriamycin contribute? Arch Dis Child 1981; 56: 544-8.

19 Alexander J, Dainiak N, Berger H J, et al. Serial assessment of doxorubicin cardiotoxicity with quantitative radionuclide angiocardiography. $N$ Engl J Med 1979; 300: 278-83.

20 Minow R A, Benjamin R S, Gottlieb J A. Adriamycin (NSC-123127) cardiomyopathy-an overview with determination of risk factors. Cancer Chemother Rep 1975; 6: 195-201.

21 Lemerle J. SIOP-UICC tumour node-metastases and staging for Wilms' tumour, neuroblastoma, and soft tissue sarcomas of childhood-a summary (abstract). In the proceedings of the Thirteenth Meeting of the International Society of Pediatric Oncology, Marseilles, September 1981: 13, 2/5.

Correspondence to Dr J Pritchard, Institute of Child Health, 30 Guilford Street, London WC1N 1EH.

Received 23 November 1981 